\title{
A Prospective Study of Surgical Site Infections in a Medical College Hospital
}

\author{
Ajeet Kumar', Bhartendu Kumar², Sunil Kumar ${ }^{2}$ \\ ${ }^{1}$ Senior Resident, Department of Surgery, SK Medical College, Muzaffarpur, Bihar, ${ }^{2}$ Associate Professor, Department of Surgery, SK Medical College, Muzaffarpur, \\ Bihar.
}

\section{Abstract}

Background: Surgical site infections (SSI) are an important post-operative complication. Knowledge about its risk factors is essential. The present study was conducted to find the profile of surgical site infection among patients admitted in surgical ward of SKMCH, Muzaffarpur. Subjects and Methods: The present cross-sectional study included 322 patients undergoing surgery. Clinical details, onset of SSI and microbiological profile were noted. Results: Mean age of the cases was 43.7 years. $61.2 \%$ of these were males. $11.8 \%$ of the cases suffered from surgical site infection. Of the emergency surgeries, $20.2 \%$ had SSI while $8.1 \%$ elective surgery cases had SSI. $36.1 \%$ of the cases with dirty wound had SSI while only $5.2 \%$ of the cases with clean wound had such infection. S. aureus was the most common organism isolated (57.9\%) followed by Pseudomonas (39.5\%) and Klebsiella (23.7\%). Conclusion: Incidence of SSI is higher in cases of emergency surgery and in dirty wounds.

Keywords: Factors, Incidence, Surgical Site Infection.

Corresponding Author: Dr. Bhartendu Kumar, Associate Professor, Department of Surgery, SK Medical College, Muzaffarpur, Bihar. Email:drpklal@gmail.com

Received: November 2019

Accepted: December 2019

\section{Introduction}

Surgical site infections (SSI) are important post-operative complication leading to increased morbidity and mortality among surgical cases. In pre-antibiotic era, the mortality rate was $70-80 \%$ in such cases. With advances in microbiology and preventive measures, the infection control has become better. Still, the rate of SSI remains high. ${ }^{[1]}$ It is reported to be the third most common nosocomial infection responsible for $12 \%-16 \%$ of all nosocomial infections among hospitalized patients. ${ }^{[2]}$

Increase in incidence of SSIs has been attributed to emergence of antimicrobial-resistant microorganisms, frequent use of indwelling devices and implants and increased longevity with resultant increase in elderly patients and those with chronic, debilitating, or immunocompromising diseases. ${ }^{[3]}$

The rate of SSI varies from $0.5-15 \%$ worldwide while studies in India reported it to be high ranging from 20-38\%. This difference is due to differences in hospital environment, surgical techniques and the hospital populations. $40-60 \%$ of these infections are preventable. ${ }^{[4]}$

Such studies have not been done in this area. Hence, this study was conducted.

\section{Aims \& objectives}

The present study was conducted to find the incidence of surgical site infection among patients admitted in surgical ward of SKMCH, Muzaffarpur during the study period, to assess the risk factors and to identify the causative organisms.

\section{Subjects and Methods}

\section{Study setting:}

The present study was conducted at the Department of Surgery, Sri Krishna Medical College, Muzaffarpur, Bihar. The institute is tertiary care center of North Bihar catering to districts of Muzaffarpur, Sitamarhi and Motihari.

\section{Duration and type of study:}

The present study was Hospital based observational in nature conducted at the Department of Surgery, Sri Krishna Medical College, Muzaffarpur between December 2017 and May 2018.

\section{Study subjects:}

Study subjects included the patients undergoing surgery in the surgery ward of the institute during the study period.

\section{Inclusion criteria:}

The patients undergoing surgery in general surgery ward as well as emergency ward were included in the present study.

\section{Exclusion criteria:}

Patients with severely contaminated wound and those undergoing surgery at some other place were excluded. 


\section{Sampling:}

All the patients admitted in the selected unit were included. A total of 322 patients were studied.

\section{Data collection procedure:}

CDC criteria for classification of surgical wounds were used and they were labelled as clean (Class I), clean contaminated (Class II), contaminated (Class III) and dirty (Class IV). Using aseptic measures, swabs were collected at the time of first dressing, then at 8 to 10 days and after 2 to 4 weeks of surgery if there was serous/ purulent discharge, signs of inflammation or wound dehiscence.

Pre-tested proforma was used for data collection which included questions regarding patient's background information, details of illness, presence of risk factors e.g. diabetes, type of surgery done, type of anaesthesia given, duration of surgery \& duration of hospital stay, nature \& severity of surgical site infection, microbiological growth and drug sensitivity.

\section{Data analysis:}

Data was entered in Microsoft Excel and analyzed using SPSS software. Percentage, proportions and contingency tables were used for description of the data. $\mathrm{P}$ value $<0.05$ was considered as statistically significant.

\section{Ethical consideration \& permission:}

Approval from Institutional Ethics Committee was obtained. Informed consent was taken from the patients. Confidentiality of records was maintained.

\section{Results}

A total of 322 patients were included in the present study. [Table 1] shows surgical scenario of the cases. $30.7 \%$ of the cases were emergency and $69.3 \%$ were elective surgeries. $11.8 \%$ of the cases suffered from surgical site infection. Of the emergency surgeries, $20.2 \%$ had SSI while $8.1 \%$ elective surgery cases had SSI. The difference among the groups was statistically significant $(\mathrm{p}=0.002)$

\begin{tabular}{|c|c|c|c|c|}
\hline $\begin{array}{l}\text { Nature of } \\
\text { surgery }\end{array}$ & $\begin{array}{l}\text { No. of } \\
\text { cases }\end{array}$ & $\begin{array}{l}\text { No. of } \\
\text { SSI }\end{array}$ & $\%$ & Significance \\
\hline Emergency & 99 & 20 & 20.2 & \multirow{3}{*}{$\begin{array}{l}X 2=9.69 \\
p=0.002\end{array}$} \\
\hline Elective & 223 & 18 & 8.1 & \\
\hline Total & 322 & 38 & 11.8 & \\
\hline
\end{tabular}

[Table 2] shows class of wound as per CDC classification. $46.6 \%$ cases had clean contaminated wound. While it was clean in $30.1 \%$. Dirty wound was seen in $11.2 \%$ cases.36.1\% of the cases with dirty wound had SSI while only $5.2 \%$ of the cases with clean wound had such infection. The difference was found to be statistically significant $(\mathrm{p}=0.000)$.

[Table 3] shows severity of SSI. Deep SSI was more commonly seen in contaminated and dirty wounds. However, this difference was not significant statistically $(\mathrm{p}=0.78)$.

Table 2: showing type of wound as per CDC classification

\begin{tabular}{|l|l|l|l|l|}
\hline Class of wound & $\begin{array}{l}\text { No. of } \\
\text { cases }\end{array}$ & $\begin{array}{l}\text { No. of } \\
\text { SSI }\end{array}$ & \% & Significance \\
\hline Clean & 97 & 5 & 5.2 & \multirow{2}{*}{$\begin{array}{l}\text { X2 }=29.5 \\
\mathrm{p}=0.000\end{array}$} \\
\cline { 1 - 4 } $\begin{array}{l}\text { Clean } \\
\text { contaminated }\end{array}$ & 150 & 12 & 8 & \\
\cline { 1 - 3 } Contaminated & 39 & 8 & 20.5 & \\
\cline { 1 - 3 } Dirty & 36 & 13 & 36.1 & \\
\hline
\end{tabular}

Table 3: showing severity of SSI

\begin{tabular}{|l|l|l|l|}
\hline Nature of wound & $\begin{array}{l}\text { Superficial } \\
\text { SSI }\end{array}$ & $\begin{array}{l}\text { Deep } \\
\text { SSI }\end{array}$ & Significance \\
\hline Clean & 3 & 3 & X2 $=1.09$ \\
\cline { 1 - 3 } Clean contaminated & 4 & 8 & \\
\cline { 1 - 3 } Contaminated & 3 & 5 & \\
\cline { 1 - 3 } Dirty & 5 & 8 & \\
\hline
\end{tabular}

[Table 4] shows comorbidities. Diabetes was seen in $36.8 \%$ cases while hypertension was seen in $26.3 \%$ cases.

Table 4: showing comorbidity $(n=38)$

\begin{tabular}{|l|l|l|}
\hline Comorbidity & No. & \% \\
\hline Diabetes & 14 & 36.8 \\
\hline Hypertension & 10 & 26.3 \\
\hline COPD & 6 & 15.8 \\
\hline None & 16 & 42.1 \\
\hline
\end{tabular}

*- multiple response

[Table 5] shows bacteria isolated from the wound. S. aureus was the most common organism isolated (57.9\%) followed by Pseudomonas (39.5\%) and Klebsiella (23.7\%).

Table 5: showing bacteria isolated from the wound

\begin{tabular}{|l|l|l|}
\hline Organism & No. & \% \\
\hline S. aureus & 22 & 57.9 \\
\hline Klebsiella & 9 & 23.7 \\
\hline Pseudomonas & 15 & 39.5 \\
\hline Citrobacter & 6 & 15.8 \\
\hline E. coli & 8 & 21.1 \\
\hline Others & 3 & 7.9 \\
\hline
\end{tabular}

*- multiple response

\section{Discussion}

Surgical site infection is one of the important complications of surgery. It leads to increased morbidity and consequential costs. Its onset depends on many factors. A total of 322 cases were studied for the incidence of surgical site infection. Mean age of the cases was 43.7 years. $61.2 \%$ of these were males. Kakati et al found that $51.53 \%$ cases were men and $48.46 \%$ were women. The mean age was 40.13 years for men $(\mathrm{CI} \pm 2.39)$ while for women it was 41.82 years $(\mathrm{CI} \pm 2.59)$. Overall mean age was 40.97 years. $^{[5]}$ Abbey et al reported that $46.1 \%$ cases were males and $53.9 \%$ were females. Maximum cases were in the age group of 26-35 years. SSI rate was similar in males and females while it was found to be significantly higher in patients aged $>56$ years. Naveen et also found that majority $(64.44 \%)$ of the cases belonged to $18-30$ years group. ${ }^{[2]}$ $30.7 \%$ of the cases were emergency and $69.3 \%$ were elective surgeries. $11.8 \%$ of the cases suffered from surgical 
site infection. Of the emergency surgeries, $20.2 \%$ had SSI while $8.1 \%$ elective surgery cases had SSI. The difference among the groups was statistically significant $(\mathrm{p}=0.002)$.

Kakati et al also found that the infection rate was found to be higher with emergency surgeries $(15.2 \%)$ than with planned elective surgeries $(4.86 \%)$ and the difference was found to be highly significant $(\mathrm{p}$ value $=0.0001) .{ }^{[5]}$ Patel et al observed that in patients with emergency surgery the infection rate was $24.14 \%$ while in patients operated electively the rate was $12.68 \%$. Overall SSI rate was $16 \%$. ${ }^{[3]}$ $46.6 \%$ cases had clean contaminated wound while it was clean in $30.1 \%$. Dirty wound was seen in $11.2 \%$ cases. $36.1 \%$ of the cases with dirty wound had SSI while only $5.2 \%$ of the cases with clean wound had such infection. The difference was found to be statistically significant $(p=0.000)$. Kakati et al reported that $7.44 \%$ cases developed SSI of which $66.66 \%$ were men and $33.34 \%$ were women. The SSI rate was found to be $3.77 \%$ in clean surgeries, $4.45 \%$ in clean contaminated surgeries, $11.02 \%$ in contaminated surgeries and $16.82 \%$ in dirty-infected surgeries. $(\mathrm{p}$ value $=0.002) \cdot{ }^{[5]}$ Abbey et al found that SSI was seen in $3.56 \%$ of clean wounds, $9.58 \%$ of clean contaminated wounds, $22.06 \%$ of contaminated and $53.45 \%$ of dirty wounds. ${ }^{[2]}$

Deep SSI was more commonly seen in contaminated and dirty wounds. However, this difference was not significant statistically $(\mathrm{p}=0.78)$. Diabetes was seen in $36.8 \%$ cases while hypertension was seen in $26.3 \%$ cases. Abbey et al observed that diabetes was present in $29.23 \%$ of cases with SSI and hypertension was seen in $16.92 \% .^{[2]}$

S. aureus was the most common organism isolated (57.9\%) followed by Pseudomonas (39.5\%) and Klebsiella (23.7\%). Kakati et al observed that Gram-negative bacilli were found in $72.54 \%$ samples and gram-positive cocci were found in $27.45 \%$ samples. None of the samples were positive for ZN staining. ${ }^{[5]}$ However, Setty et al found that among the 39 SSIs, 36 showed growth of colonies. Staphylococcus aureus was the predominant organism isolated from the surgical sites followed by Pseudomonas and Klebsiella. Some surgical sites had mixed infections involving multiple organisms. ${ }^{[6]}$ Patel et al found that the pathogens were Escherichia coli (35.7\%), Klebsiella spp (21.4\%),
Coagulase negative Staphylococci $(14.3 \%)$, Pseudomonas aeruginosa (14.3\%), Staphylococcus aureus $(7.1 \%)$ and Proteus mirabilis $(7.1 \%){ }^{[3]}$

The occurrence of surgical site infection is dependent upon multiple factors. The nature of surgery, the surgical setting in which it is performed, the type of wound etc. determine its onset. ${ }^{[2]}$ Use of prophylactic antibiotics is also one of the important factors and the choice of antibiotic to be used depends upon the local prevalent pattern. The findings of this study are similar to that observed in other studies. The pattern of bacteriological isolates is different and will be helpful to the surgeons in proper management of such cases.

\section{Conclusion}

The overall rate of surgical site infection (SSI) was $11.8 \%$. The rate of SSI was higher in emergency cases $(20.2 \%)$ as compared to elective ones $(8.1 \%)$. It was more commonly seen in dirty wounds than other types $(\mathrm{p}=0.000)$. S. aureus, Pseudomonas and Klebsiella were the common organisms isolated. Awareness about risk factors and proper antibiotic prophylaxis are essential to prevent such infections.

\section{References}

1. Kumar A, Rai A. Prevalence of surgical site infection in general surgery in a tertiary care centre in India. Int Surg J 2017;4:3101-6.

2. Abbey R, Mohan M, Malik N, Tiwari R, Nahar S. Surgical Site Infections in a Rural Teaching Hospital of North India. International Journal of Advanced and Integrated Medical Sciences 2017;2:11-6.

3. Patel S, Patel M, Patel S, Soni S, Kinariwala D, Vegad M. Surgical Site Infections: Incidence and Risk Factors in a Tertiary Care Hospital, Western India. Natl J Community Med 2012;3:193-6.

4. Anand S, Verma V, Arora B, Dahiya R. A Clinico Bacteriological Study of Post Operative Wound Infection. IOSR J Dent Med Sci (IOSR-JDMS) 2016;15:57-60.

5. Kakati B, Kumar A, Gupta P, Sachan P, Thakuria B. Surgical site abdominal wound infections: Experience at a north Indian tertiary care hospital Natl J Community Med 2013;14:7-12.

6. Setty NK, Nagaraja M, Nagappa D, Laxmipathy Naik RM, Giriyaiah C, Gowda N. A study on Surgical Site Infections (SSI) and associated factors in a government tertiary care teaching hospital in Mysore, Karnataka. Int J Med Public Health 2014;4:171-6.

Copyright: (C) the author(s), 2020. It is an open-access article distributed under the terms of the Creative Commons Attribution License (CC BY 4.0), which permits authors to retain ownership of the copyright for their content, and allow anyone to download, reuse, reprint, modify, distribute and/or copy the content as long as the original authors and source are cited.

How to cite this article: Kumar A, Kumar B, Kumar S. A Prospective Study of Surgical Site Infections in a Medical College Hospital. Asian J. Med. Res. 2020;9(1):SG01-SG03.

DOI: dx.doi.org/10.47009/ajmr.2020.9.1.SG1

Source of Support: Nil, Conflict of Interest: None declared. 